\title{
TEORIA DOS JOGOS E SELEÇÃO DE PORTFÓLIO: UMA PROPOSTA DE ADAPTAÇÃO AO MODELO MINIMAX E APLICAÇÃO AO MERCADO ACIONÁRIO BRASILEIRO ${ }^{1}$
}

\author{
Christiano Alves Farias ${ }^{2}$ \\ Wilson da Cruz Vieira ${ }^{3}$ \\ Maurinho Luiz dos Santos ${ }^{3}$
}

Resumo - O objetivo deste trabalho foi comparar e analisar os modelos de seleção de portfólio Média-Variância (MV), Minimax e Minimax Ponderado (MP), aplicados ao mercado acionário brasileiro. Foram consideradas as 50 ações mais negociadas na Bovespa, nos períodos de setembro de 1999 a agosto de 2000; janeiro a dezembro de 2001; e fevereiro de 2002 a janeiro de 2003. Os modelos geraram portfólios ótimos para cada mês, com base em retornos dos últimos 12 meses. O modelo MV proporcionou portfólios que, em certas circunstâncias, obtiveram retorno superiores e, em outras, inferiores ao Ibovespa. O Minimax destacou-se por apresentar maiores retornos acumulados ao final do período em que os portfólios foram gerados pelo MP, MV e Ibovespa. Os modelos Minimax e MP geraram portfólios que apresentaram retornos acumulados maiores que o referido índice, nos três períodos analisados.

Palavras-chave: seleção de portfólio, média-variância, Bovespa, teoria de jogos.

\section{Introdução}

Um investidor, quando realiza seu investimento, deve escolher os ativos que irão compor seu portfólio ${ }^{4}$ e a parcela do seu orçamento que será destinada a cada um deles. Caso seja racional, ele buscará obter o maior

\footnotetext{
${ }^{1}$ Recebido em 10/12/200. Aceito em 28/01/2004.

${ }^{2}$ Mestre em Economia Aplicada pelo Departamento de Economia Rural da Universidade Federal de Viçosa. CEP 36570-000, Viçosa - MG.

${ }^{3}$ Professores do Departamento de Economia Rural da Universidade Federal de Viçosa. CEP 36570-000, Viçosa - MG.

${ }^{4}$ Portfólio, ou carteira de títulos, pode ser definido como o conjunto de ativos financeiros (ações, debêntures, etc.) adquiridos por um investidor, seja ele pessoa física ou jurídica (Sandroni, 2000).
} 
retorno possível, a dado nível de risco, ou, de forma análoga, o menor risco, a determinado nível de retorno.

A teoria dos jogos tem se mostrado capaz de representar e solucionar situações que envolvem a tomada de decisão sob condições de risco, demonstrando, assim, grande potencial de aplicações em áreas como seleção de portfólio. Dessa forma, o problema do investidor pode ser bem representado por essa teoria.

Um dos primeiros trabalhos aplicado nessa área, usando a teoria dos jogos, foi feito por Young (1998), que utilizou o critério Minimax para formulação do modelo. Neste artigo, buscou-se realizar uma adaptação ao modelo Minimax para seleção de portfólio, o que resultou em um modelo denominado Minimax Ponderado (MP). No MP procurou-se introduzir uma nova forma de mensuração do risco, conservando a idéia principal do Minimax, que é a de selecionar a melhor situação dentre as piores. Esses dois modelos são formulados com equações lineares, são resolvidos por programação linear e apresentam uma abordagem diferente da tradicional Teoria do Portfólio.

Markowitz (1952) introduziu os princípios da Teoria do Portfólio em seu artigo "Portfólio Selection". Nesse artigo, demonstrou que a diversificação na composição do portfólio do investidor, entre os diferentes ativos, pode trazer maiores benefícios em comparação com portfólios formados apenas por um ativo, uma vez que a diversificação pode diminuir o risco do investimento, dado o nível de retorno. O modelo de Markowitz é denominado Média-Variância (MV) e tem formulação quadrática.

Sharpe (1971, p.15) já havia notado que o problema da análise de portfólio poderia ser expresso, adequadamente, por meio de funções lineares e resolvido, de maneira eficiente, por Programação Linear. Destacou que, se isso ocorresse, seriam enormes as vantagens ... se a essência do problema de análise de portfólio puder ser adequadamente capturada de forma hábil para métodos de Programação Linear, as perspectivas para aplicações práticas deveriam ser grandemente realçadas. 
Dessa forma, visto que a Programação Linear vem se tornando o padrão característico de otimização disseminado nos programas dos computadores pessoais, os modelos Minimax e MP apresentam substanciais atrativos devido às suas fáceis formulações lineares. Por isso, esses modelos apresentam grande potencial para se tornarem ferramentas na otimização de portfólio, acessíveis a todos os administradores financeiros.

Neste trabalho foi realizada uma aplicação dos modelos no mercado acionário brasileiro. Buscou-se analisar o desempenho dos portfólios gerados a partir dos modelos citados (MV, Minimax e MP), envolvendo tanto a alta de mercado como a baixa. Assim, foram escolhidos três períodos distintos (setembro de 1999 a agosto de 2000; janeiro a dezembro de 2001; e fevereiro de 2002 a janeiro de 2003), com o objetivo de avaliar os modelos em cenários diferentes. No primeiro período houve alta de mercado e, nos dois últimos, baixa.

Portanto, procurou-se avaliar os portfólios selecionados pelos três modelos, com número de 50 ações, em três diferentes cenários. Essa avaliação é importante para orientar o investidor na escolha do modelo de seleção do portfólio em diversas condições econômicas, visto que a maneira como o investidor toma suas decisões de investimentos, entre as diferentes ações e os instrumentos que utiliza para se orientar na formação de seu portfólio, constitui questão fundamental para alocação dos seus recursos de maneira eficiente. Dessa forma, buscou-se, neste trabalho, avaliar os instrumentos que auxiliem na seleção de portfólios que maximizem os benefícios da atuação do investidor no mercado acionário brasileiro.

De forma resumida, o objetivo deste artigo foi fazer uma aplicação dos três modelos no mercado acionário brasileiro, nos períodos de setembro de 1999 a agosto de 2000, janeiro a dezembro de 2001 e fevereiro de 2002 a janeiro de 2003, e verificar se a utilização dos três modelos permitiu a obtenção de resultados melhores que o Ibovespa e se algum modelo apresentou desempenho superior ao outro. 


\section{Metodologia}

\subsection{Teoria do portfólio ${ }^{5}$}

Esta teoria procura mostrar como se dão as decisões sobre investimentos dos agentes, em uma situação que envolve risco. Assim, de acordo com a teoria do portfólio, são estimados retornos esperados aos quais são atribuídas probabilidades de ocorrência baseadas na função de utilidade do investidor, de forma a construir uma função de frequiência destes. Considera-se a medida de tendência central desta função de freqüência como apropriada para representar o retorno do ativo.

De forma semelhante, com base na função de freqüência do retorno esperado, é considerado o desvio-padrão ${ }^{6}$, que é a medida de dispersão em torno da média, como medida apropriada de risco do ativo.

A abordagem quantitativa, apresentada por Markowitz (1952), utiliza a variância como forma de mensuração do risco, denominada de MédiaVariância (MV). Este trabalho é, hoje, reconhecido como o ponto de partida da moderna teoria do portfólio. Nesta abordagem, é proposta a escolha do portfólio que minimize a variância, sujeito à restrição de dado retorno médio. O problema de otimização de portfólio considerado neste trabalho é a original formulação de Markowitz e é baseado em modelo de um único período e investimento.

Na aplicação da teoria podem ser usadas séries de retornos de ativos individuais.

Conforme Young (1998), o modelo Média-Variância pode ser descrito da seguinte forma:

\footnotetext{
${ }^{5}$ Ver, por exemplo, Markowitz (1952).

${ }^{6}$ É importante notar que Makowitz não sugeriu o uso de dados históricos para estimação da matriz de covariância utilizada no modelo. Porém, este procedimento tem sido adotado largamente nos trabalho que utilizam o modelo que admite que os dados históricos proporcionam uma adequada matriz de covariância.
} 


$$
\underset{w}{\operatorname{Min}} \sum_{j=1}^{N} \sum_{k=1}^{N} w_{j} w_{k} s_{j k}
$$

sujeito a

$$
\sum_{j=1}^{N} w_{j} \bar{y}_{j} \geq G
$$

$\sum_{j=1}^{N} w_{j}=W$

$0 \leq w_{j} \leq u_{-}, j=1, \ldots, n$ e $k=1, \ldots, N$,

em que $s_{j k}=\frac{1}{\mathrm{~T}-\mathrm{N}} \sum_{t=1}^{T}\left(y_{j t}-\bar{y}_{k}\right)\left(\mathrm{y}_{\mathrm{kt}}-\bar{y}_{k}\right)$, para um número finito de ativos financeiros, $\mathrm{N}$, e períodos de tempo, $\mathrm{T} ; y_{j t}$, retorno por unidade monetária investida no ativo $\mathrm{j}$, no período de tempo $\mathrm{t} ; \bar{y}_{j}$, retorno médio do ativo $\mathrm{j} ; y_{k t}$, retorno por unidade monetária investida no ativo $\mathrm{k}$, no período de tempo $\mathrm{t} ; \overline{y_{k}}$, retorno médio do ativo $\mathrm{k} ; \sum_{j=1}^{N} w_{j} \bar{y}_{j}$, retorno médio do portfólio; $\mathrm{w}_{\mathrm{j}}$ e $w_{k}$, alocações do portfólio para os ativos j e k, respectivamente; e $u_{j}$, valor máximo da parcela do orçamento que pode ser alocada no ativo $\mathrm{j}$.

A Média-Variância, como modelo de seleção, representa o portfólio que minimiza o valor da expressão dada por (1), sujeito à restrição de que o retorno médio do portfólio (2) supere determinado nível, que se chama de $G$, e que a soma das alocações do portfólio (3) não possa exceder o valor total do orçamento, W. 
Segundo Markowitz (1952), é confirmada a crença, que havia nos investidores, de que eram obtidos benefícios em se compor o portfólio com mais de um ativo, devido à redução do risco em um portfólio diversificado. Para verificar e analisar os benefícios da diversificação, examinase se os retornos esperados movem-se na mesma direção ou em direções opostas. Para isto, é introduzida na análise uma medida de correlação entre os retornos dos ativos que poderiam fazer parte do portfólio.

Um resultado importante desta análise é que, à medida que a correlação entre os ativos diminui, ocorre aumento dos benefícios da diversificação na composição do portfólio, ou seja, há diminuição do risco para um mesmo nível de retorno. De modo geral, quanto mais baixa for a correlação entre os retornos dos ativos, maior será o potencial de diversificação dos riscos.

O modelo MV será válido: (i) se os retornos dos ativos individuais possuírem distribuição normal; e, ou, (ii) se o investidor for avesso ao risco, caso prefira menor desvio-padrão ao maior. Muitas teorias em finanças são baseadas neste modelo, no entanto, parece que o próprio modelo não vem sendo usado, em sua forma original, por profissionais de mercado como ferramenta para otimização do portfólio de larga escala. Konno e Yamazaki (1991) destacaram ainda que, de acordo com gestores de risco, os problemas de otimização quadrática que contêm mais de 200 variáveis são raramente resolvidos na prática.

As principais razões que causam a não-utilização do problema de otimização de Markowitz, para portfólios de larga escala (que contêm grande número de ativos e, ou, muitas funções de restrições), na prática, são:

a) Dificuldades Computacionais - Para operacionalizar o modelo são necessários $n(n+1) / 2$ cálculos que constam em uma matriz de covariância, por meio de dados históricos ou projeções futuras. Isso faz com que os profissionais que atuam no mercado não se sintam estimulados a usar tal modelo, devido, principalmente, aos tediosos cálculos. Além disso, por possuir uma função objetivo não-linear (visivelmente quadrática), 
torna-se muito difícil encontrar soluções quando o número de ativos é grande (Papahristodoulou, 2003). Essas dificuldades computacionais, como ressaltado anteriormente, são substancialmente aliviadas pelo uso de modelo de Índices (Sharpe, 1963; Perold, 1984) e técnicas que usam matrizes desenvolvidas por Pang (1980) e Perold (1984); mesmo assim, não são fáceis de serem obtidas soluções, em larga escala, para problemas de Programação Quadrática, em tempo viável.

b) Percepção do investidor quanto ao risco e à distribuição dos preços das ações - Muitos praticantes do mercado não estão convencidos da validade do desvio-padrão como adequada mensuração do risco (Kroll et al., 1984; Young, 1998). A percepção do investidor quanto ao risco pode não ser simétrica. Assim, o modelo de Markowitz deveria ser visto como uma aproximação do problema de otimização do investidor.

c) Transações/Administração de custos e eliminação de efeito Numa solução ótima $x^{*}=\left(x_{1}^{*}, \ldots, \mathrm{x}_{\mathrm{n}}{ }^{*}\right)$ de um problema de Programação Quadrática de larga escala, usualmente, há muitos elementos com valores positivos diferentes de 0 . De fato, esperam-se 100 a 200 componentes de $x^{*}$ com valor positivo, quando $n$ for maior ou igual a 1000. Segundo Papahristodoulou (2003), as soluções obtidas pelo modelo MV são, muitas vezes, mínimos locais, ou soluções subótimas e, se o número de ativos for maior que 500, provavelmente mais de 200 ativos terão valores positivos nas soluções. Isso significa que o investidor tem de adquirir muitas ações diferentes, muitas das quais podem ser frações de $1 \%$ do orçamento total. Esse fato constitui um grande inconveniente na prática, visto que o investidor terá de alocar parte do seu orçamento em grande número de pequenas parcelas, além de não poder comprar pequeno montante de ações abaixo da unidade mínima de transação. Dessa forma, tornam-se necessários a seleção de múltiplos inteiros da unidade mínima de transação e a resolução de um problema de Programação Quadrática Inteira, o qual será inviável se o número de ativos for grande. Especialistas de mercado ressaltam que a resolução de problemas quadráticos inteiros, com pequeno número de ativos, 20 por exemplo, seria difícil; no entanto, administrar um portfólio de 100 ativos seria 
extremamente difícil ou, muitas vezes, impossível (Konno e Yamazaki, 1991).

Essas observações motivaram e têm motivado autores a aperfeiçoar o modelo MV e a apresentar novos modelos, tanto teóricos como computacionais.

\subsection{Modelos analíticos}

Os modelos analíticos utilizados neste trabalho foram o Minimax e o Minimax Ponderado (MP), que objetivam servir de ferramentas alternativas para seleção de portfólios ao investidor em ativos de renda variável. Esses dois modelos, por serem expressos em formas lineares e resolvidos por simples Programação Linear, apresentam nítida vantagem sobre o MV, que tem forma quadrática.

O Minimax têm sido utilizado largamente na literatura e apresenta também mensuração de risco alternativa com propriedades computacionais atrativas. Tem tido bons resultados, quando comparado com outros modelos de seleção de portfólios. ${ }^{7} \mathrm{O}$ modelo tem se destacado por constituir uma forma distinta, baseada na teoria dos jogos, de seleção de portfólio. O MP apresenta uma adaptação, proposta neste trabalho, ao Minimax, alterando, basicamente, a forma como este considera o risco e conservando as vantagens computacionais advindas da sua formulação com equações lineares.

\subsubsection{Modelo Minimax}

O modelo Minimax para seleção de portfólio baseia-se na teoria dos jogos. Em um jogo podem existir dois ou mais jogadores que sabem os objetivos dos seus adversários. Visto que cada jogador age racionalmente, a teoria dos jogos pode apresentar solução para essas situações, ad-

${ }^{7}$ Ver, por exemplo, Farias (2003) 
mitindo-se que eles procurem maximizar os retornos mínimos esperados ou, de forma equivalente, procurem minimizar as máximas perdas esperadas (Weber, 1986).

A teoria dos jogos é muito útil para solucionar situações que envolvem tomada de decisão dos agentes sob condições de risco. Apesar de essas situações, muitas vezes, envolverem somente um agente, o modelo Minimax tem-se mostrado apropriado para solucionar tais situações, desde que se considere o estado de natureza como o outro agente do jogo e desde que o jogador, que toma as decisões, vise proteger-se contra a pior ocorrência possível.

De acordo com Young (1998), a formulação do modelo Minimax para seleção de porfólio pode ser descrita da seguinte forma. Para um número finito de ativos financeiros, $\mathrm{N}$, e períodos de tempo, $\mathrm{T}$, tem-se:

$\overline{\mathrm{y}}_{\mathrm{j}}=\frac{1}{T} \sum_{t=1}^{T} y_{j t}$,

$E_{p}=\sum w_{j} \bar{y}_{j}$

$y_{p t}=\sum_{j=1}^{N} w_{j} y_{i t}$

$M_{p}=\min _{t} y_{p t}$

em que $y_{i t}$ é o retorno por unidade monetária investida no ativo j, no período de tempo t; $y_{i t}$, retorno por unidade monetária investida no ativo i, no período t; $\bar{y}_{j}$, retorno médio do ativo $\mathrm{j} ; w_{j}$, alocação do portfólio para o ativo $\mathrm{j} ; \quad y_{p t}$, retorno do portfólio, no período t; $E_{p}$, retorno 
médio do portfólio, no período t; e $M_{p}$, retorno mínimo do portfólio, por período. ${ }^{8}$

O Minimax, como modelo de seleção de portfólio, representa o máximo do valor de $M_{p}$, sujeito à restrição de que $E_{p}$ supere determinando nível, que se chama de $G$, e que a soma das alocações dos portfólios não possa exceder o valor total do orçamento, W, ou seja, o portfólio que minimiza o máximo prejuízo, que é definido como o ganho negativo ou, de forma equivalente, que maximiza o mínimo ganho.

A solução deste problema pode ser dada por Programação Linear, como descrito a seguir:

$\operatorname{Max} M$

$$
M_{p}, w
$$

sujeito a

$$
\begin{aligned}
& \sum_{j=1}^{N} w_{j} y_{j t}-M_{p} \geq 0, \quad t=1, \ldots . ., T \\
& \sum_{j=1}^{N} w_{j} \overline{y_{j}} \geq G \\
& \sum_{J=1}^{N} w_{j} \leq W \\
& O \leq w_{j} \leq u_{j}, j=1, \ldots, n .
\end{aligned}
$$

O portfólio escolhido pelo modelo é o que minimiza o máximo prejuízo sobre observações de períodos passados, a dado nível de retorno

\footnotetext{
${ }^{8}$ Esta formulação se refere mais à descrição do critério Maximin de seleção de portfólio; porém, o termo Minimax foi usado, uma vez que este é o mais utilizado na literatura especializada para esta formulação. Porém, faz-se necessário ressaltar que a formulação apresentada, na verdade, é o critério Maximin, e não a sua forma dual Minimax.
} 
(Minimax). A forma dual é o que maximiza o mínimo retorno sobre observações de períodos passados (Maximin).

A essência do modelo poderá ser mais facilmente compreendida, caso se analise o modelo partindo das equações que o compõem. A equação (10) assegura que, para cada período, a variável $M_{p}$ será sempre menor ou igual ao retorno do portfólio $\left(\sum_{j=1}^{N} w_{j} y_{j t} \geq M_{p}, \mathrm{t}=1, \ldots, \mathrm{T}\right)$. Portanto, $M_{p}$ representará o "mínimo" retorno do portfólio em cada período ou, no máximo, um retorno igual. Se $M_{p}$ for maximizado, o portfólio terá o valor máximo dos mínimos retornos (Maximin) ou o mínimo das máximas perdas $\left(\operatorname{Minimax}^{9}\right)$.

\subsubsection{Minimax Ponderado (MP)}

O modelo Minimax Ponderado é uma adaptação ao modelo Minimax, originalmente apresentado por Young. O MP busca a maximização do mínimo retorno do portfólio, em que os retornos de cada ativo são ponderados pelo inverso das suas variâncias, no horizonte de tempo passado considerado.

O Minimax original não faz nenhuma referência explícita ao risco dos ativos. Nesse modelo, os ativos selecionados poderiam apresentar grande volatilidade, a dado retorno, resultando, assim, em pequena razão retorno/risco. Poderiam ainda ser selecionados para compor o portfólio ótimo gerado pelo modelo. Porém, outros ativos, apesar de apresentarem baixa volatilidade e retorno um pouco menor do que o ativo citado anteriormente, mas proporcionarem maior razão retorno/risco, poderiam não ser selecionados.

\footnotetext{
${ }^{9}$ Para maiores informações sobre o modelo Minimax para seleção de portfólio, ver Young (1998).
} 
Por isso, a equação (12) foi modificada para:

$$
\sum_{j=1}^{N} w_{j} \frac{y_{j t}}{\delta_{j t}}-M_{p} \geq 0, \quad \mathrm{t}=1, \ldots, \mathrm{T}
$$

em que $\delta_{j t}$ representa a variância de cada ativo, no período t. As demais variáveis são as mesmas definidas no modelo Minimax anterior.

Dessa forma, como ressaltado anteriormente, na seleção dos ativos não se consideraria apenas seu retorno, mas sua razão retorno/risco $\left(y_{j t} / \delta_{j t}\right)$, e a variância de cada ativo seria a medida apropriada de seu risco. Portanto, quanto maior o retorno de um ativo, a dado risco, maior seria o seu peso na composição do portfólio. De forma análoga, a dado retorno, quanto maior sua variância, menor seria seu peso na composição do portfólio. Assim, foi introduzida uma nova forma de mensurar o risco por meio do modelo, conservando-se a idéia do Minimax, que é escolher, dentre as piores situações, a melhor. Contudo, no MP, as piores situações passaram a ser representadas pelas menores razões retorno/risco. Com isso, o retorno de cada ativo é ponderado pelo seu respectivo risco.

O novo modelo é representado da seguinte forma:

$$
\underset{M_{p}, w}{\operatorname{Max}} M_{p},
$$

sujeito a

$$
\begin{aligned}
& \sum_{j=1}^{N} w_{j} \frac{y_{j t}}{\delta_{j t}}-M_{p} \geq 0, t=1, \ldots, \mathrm{T}, \\
& \sum_{j=1}^{N} w_{j} \overline{y_{j}} \geq G,
\end{aligned}
$$




$$
\begin{aligned}
& \sum_{J=1}^{N} w_{j} \leq W \\
& 0 \leq \mathrm{w}_{\mathrm{j}} \leq \mathrm{u}_{\mathrm{j}}, \mathrm{j}=1, \ldots, \mathrm{n} .
\end{aligned}
$$

em que todas as variáveis foram definidas anteriormente.

\subsection{Operacionalização dos modelos e fonte de dados}

A projeção do portfólio ótimo foi feita sempre para o período de um mês. Com vistas em selecionar o portfólio sugerido para investimento em determinado mês, foram utilizados dados mensais de um horizonte de 12 meses e não foram considerados quaisquer custos de transação ${ }^{10} \mathrm{e}$, ou, tributos, além de se admitir válida a compra de ações em qualquer quantidade, inclusive frações. $\mathrm{O}$ valor máximo da parcela do orçamento $\left(u_{j}\right)$, que foi permitido que se alocasse em um único ativo, foi de $75 \%$.

Dessa forma, no portfólio selecionado no mês de janeiro de 2001, por exemplo, utilizaram-se os retornos das ações dos meses de janeiro a dezembro de 2000; no mês de fevereiro de 2001, fez-se uso dos retornos dos ativos dos últimos 12 meses (fevereiro de 2000 a janeiro de 2001) e, assim, obteve-se o portfólio ótimo para cada mês selecionado ${ }^{11}$. Esse tipo de procedimento tem sido usado por vários autores ${ }^{12}$, na literatura especializada.

Foram analisados os portfólios selecionados a partir dos modelos MV, Minimax e MP, considerando-se 50 ações, em três períodos, as quais foram ordenadas segundo a liquidez que apresentavam em janeiro de 2001. Essas ações e seus respectivos retornos podem ser encontrados na site da Bovespa (http://www.bovespa.com.br).

\footnotetext{
${ }^{10}$ Gastineau e Kritzman (1996) definiram custo de transação como o "custo de compra ou venda de um instrumento financeiro avaliado dentro do contexto de seu impacto sobre a carteira, que inclui qualquer corretagem sobre compra ou venda e parte do diferencial entre ofertas de compra e venda".

${ }^{11}$ A escolha ótima da alocação do orçamento, em cada mês, foi denominada de termo de simulação.

${ }^{12}$ São alguns desses autores: Konno e Yamazaki (1991), Young (1998), Papahristodoulou (2003), Simaan (1997), Sharpe (1971) e Figueiredo et al. (2000).
} 
Buscou-se selecionar três períodos para análise dos portfólios gerados pelos modelos, no intervalo de setembro 1999 a janeiro de 2003 . O primeiro período foi de setembro de 1999 a agosto de 2000; o segundo, de janeiro de 2001 a dezembro de 2001; e o terceiro, de fevereiro de 2002 a janeiro de 2003. O primeiro correspondeu ao período de alta de mercado, enquanto o segundo e o terceiro, a períodos de baixa. Em cada período foram realizadas 12 simulações por modelo. Três modelos e três períodos foram utilizados; assim, em todo o estudo foram realizadas 108 simulações $(12 * 3 * 3)$.

Dessa forma, analisou-se o comportamento dos portfólios selecionados pelos modelos, em três distintos cenários. Apesar de dois períodos serem de baixa de mercado, eles podem apresentar caraterísticas diferentes que influenciem os resultados, uma vez que o portfólio de um mês é gerado com base nos 12 meses que o antecedem e que apresentaram características distintas.

Na seleção de portfólios de investimentos, a partir dos modelos, foi utilizada a planilha eletrônica Microsoft Excel. Na realização deste trabalho foram empregados dados referentes aos retornos proporcionados por 50 ações negociadas na Bolsa de Valores do Estado de São Paulo (Bovespa), as quais compuseram o Índice $\mathrm{IBX}^{13}$, da Bolsa de Valores de São Paulo, em janeiro de 2001.

$\mathrm{O}$ ativo livre de risco, considerado neste trabalho, foi a taxa do Certificado de Depósito Interbancário (CDI), e a carteira representativa de mercado foi representada pelo Índice da Bolsa de Valores de São Paulo (Ibovespa ${ }^{14}$ ).

\footnotetext{
13 Índice Brasil (IBX) é composto pelas 100 ações mais negociadas e de maior volume financeiro no período de 12 meses e é reavaliado a cada quatro meses. Para fazer parte do índice, a ação precisa atender aos seguintes critérios (sempre referentes aos doze meses anteriores à formação da carteira): estar entre as 100 melhores classificadas quanto ao seu índice de negociabilidade; ter sido negociada em pelo menos $70 \%$ dos pregões ocorridos nos doze meses anteriores à formação da carteira do índice (BOVESPA, 2003). Maiores informações sobre o referido índice estão disponíveis na internet no endereço: (http://www.bovespa.com.br).

${ }^{14}$ Para a escolha dos papéis, a Bovespa considera o número de negócios e o volume movimentado em um período de 12 meses. Isso significa que cada ação tem um peso diferente no índice. A composição do Ibovespa, as 54 ações, é reavaliada a cada quatro meses, a fim de manter o índice representativo. Matematicamente, o Ibovespa é a soma dos pesos desses papéis, ou seja, a quantidade teórica da ação multiplicada pelo último preço do papel. Quando foi lançado, em 1968, o índice marcava 100 pontos. Informações adicionais podem ser obtidas no endereço: (http://www.bovespa.com.br).
} 
O Ibovespa mede as variações dos preços das ações das empresas mais negociadas na Bolsa de Valores de São Paulo. A variação do Ibovespa serve como parâmetro indicativo de rentabilidade esperada de alguns fundos de ações. O índice de uma bolsa de valores proporciona parâmetros de variação de valores ao mercado, ou seja, é útil para que o investidor possa saber se, naquela bolsa, em média, os papéis estão valorizando ou desvalorizando. Esse índice é considerado o termômetro do mercado, visto que mede o desempenho das 54 ações mais negociadas (julho/03), o que representa mais de $80 \%$ do volume total negociado na Bovespa (Bovespa, 2003).

As cotações e os índices foram obtidos do banco de dados da Economática Software para Investimentos Ltda., no período de setembro de 1998 a janeiro de 2003. Todas as cotações foram ajustadas a eventuais distribuições de dividendos e, ou, bonificações e deflacionadas pelo Índice Geral de Preços - Disponibilidade Interna Acumulado (IGPDI Acumulado), calculado pela Fundação Getúlio Vargas. A taxa mensal do CDI foi coletada no site do IPEA (http://www.ipeadata.gov.br/).

\section{Resultados e discussão}

Os resultados foram divididos em três grupos, conforme o período de tempo: de setembro de 1999 a agosto de 2000; de janeiro de 2001 a dezembro de 2001; e de fevereiro de 2002 a janeiro de 2003. Dessa forma, foram apresentados, primeiro, os resultados de setembro de 1999 a agosto de 2000, gerados pelos modelos a partir da utilização das 50 ações escolhidas. O mesmo procedimento foi utilizado nos demais períodos.

O modelo MV, que admite a forma de minimização (função objetivo), apresentou alguns problemas. Quando se permitiu que este pudesse utilizar parcialmente o orçamento em suas soluções, quase sempre independente do cenário, as variáveis que representavam a parcela do orçamento a ser investida em cada ativo tiveram valor 0. Esse fato é com- 
preensível e, de certa forma, esperado, uma vez que, quando não há nenhuma equação que restrinja um nível mínimo de utilização do orçamento, as variáveis em que este deveria ser alocado tendem a ser zero, pois a função objetivo que as relaciona está sendo minimizada.

Diversos autores, como Konno e Yamazaki (1991) e Papahristodoulou (2003), têm imposto a restrição de que todo o orçamento seja alocado, o que, porém, pode gerar soluções que se afastem dos valores ótimos. Contudo, se não fosse imposta essa restrição, haveria grandes dificuldades na análise dos resultados desses modelos, uma vez que, nas soluções encontradas, a parcela do orçamento que deveria ser alocada em cada ativo seria zero. Diante disso, optou-se, neste trabalho, por utilizar a restrição de que todo orçamento seja alocado nos ativos considerados.

Já os modelos que admitiram a forma de maximização (Minimax e MP) não apresentaram tal problema, uma vez que, ao ser permitido que o orçamento seja parcialmente alocado, o solver buscará alocar o maior valor possível deste para obter a melhor solução.

\subsection{Resultados do $1^{\circ}$ período ${ }^{15}$ : setembro de 1999 a agosto de 2000}

O desempenho, em termos de retorno, dos modelos do Ibovespa e da taxa livre de risco é apresentado na Figura 1. Como pode-se observar, todas as estratégias baseadas nos modelos estudados obtiveram resultados consideravelmente superiores ao CDI, durante todo o período.

O melhor resultado, ao final do período, foi obtido pelo portfólio do modelo Minimax, seguido de MP e MV. Os portfólios de Minimax e MP apresentaram resultados semelhantes, considerando-se somente os retornos acumulados, tendo o primeiro um retorno pouco maior, durante todo o período, e 2,99\% a mais que o MP, ao final deste.

${ }^{15}$ Neste período, em todas as soluções, o orçamento foi utilizado por completo. 
Os retornos excedentes ${ }^{16}$, apresentados pelos portfólios selecionados pelos modelos ao final do período, foram de 44,08, 41,09 e 29,92 pontos percentuais para Minimax, MP e MV, respectivamente. Esses dados destacam os excelentes resultados obtidos, quando se analisam somente os retornos, pelos portfólios dos modelos Minimax e MP, que demonstraram ser nitidamente superiores ao MV.

A Figura 1 apresenta retornos acumulados dos portfólios gerados pelos modelos e pelo Ibovespa. Os gerados pelos modelos ora apresentavam retornos acumulados superiores, ora inferiores ao índice de mercado (Ibovespa); porém, ao final do período todos os modelos obtiveram desempenho superior ao índice analisado. Destacou-se o portfólio do Minimax, uma vez que este obteve retornos acumulados maiores que o índice, em mais de três dos quartos períodos analisados.

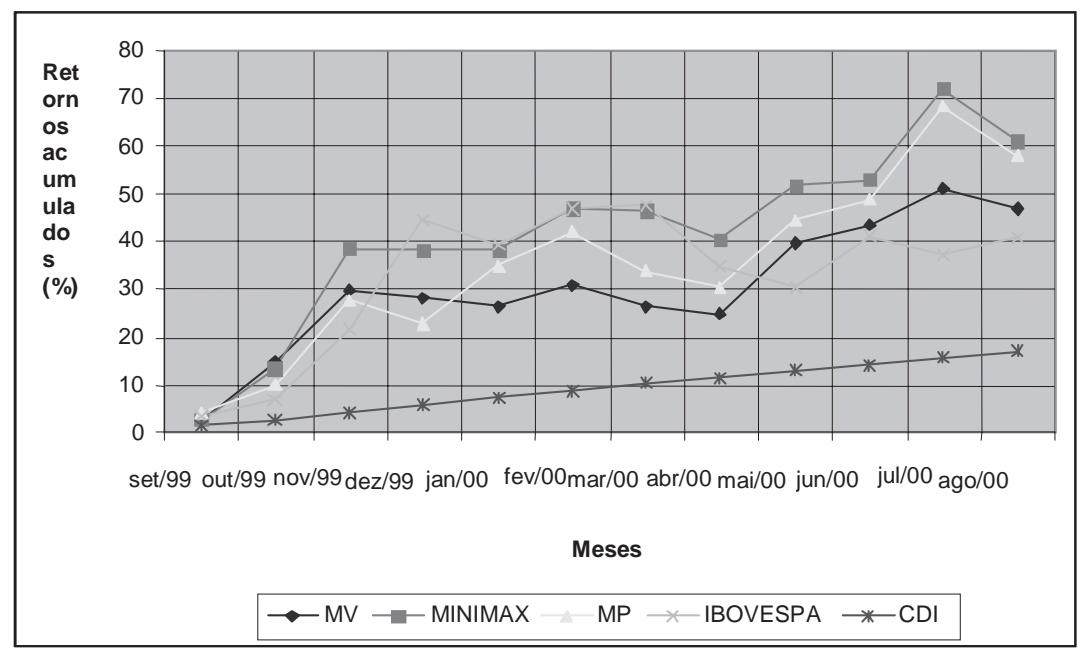

Fonte: Farias (2003).

Figura 1 - Retornos acumulados pelos portfólios selecionados, Ibovespa e CDI, utilizando-se 50 ações (set. 1999 - ago. 2000).

\footnotetext{
${ }^{16}$ Retornos excedentes podem ser entendidos como retornos acumulados subtraídos da taxa livre de risco. O retorno, excedente mensal é dado pela seguinte expressão: $E x=T-L$, em que T é o retorno médio mensal do portfolio; e, L, taxa média mensal do ativo livre de risco.
} 
Até esse momento, somente foram analisados os retornos proporcionados pelos portfólios; porém, é imprescindível analisar os riscos associados a cada uma das alternativas de investimento, ou melhor, a relação retorno-risco. Para isso, foi feito uso do Índice de Sharpe ${ }^{17}$, que relaciona o retorno excedente com o desvio-padrão. O retorno excedente, como ressaltado, é a diferença entre o retorno do portfólio e a taxa do CDI. O retorno excedente médio é a média dos retornos excedentes mensais. Torna-se interessante classificar um portfólio por este índice, de forma que, quanto mais alto for o valor, mais eficiente ele será, pois apresentará maior relação retorno-risco, ou retorno excedente-risco. No início da Tabela 1, são apresentados os retornos médios, o desvio-padrão, como medida de risco, e o índice de Sharpe para os portfólios selecionados pelos modelos.

O valor do índice de Sharpe, apresentado pelo portfólio selecionado pelo Minimax, foi de 0,354, seguido do MP, MV e Ibovespa, com 0,348, 0,347 e 0,206, respectivamente. Dessa forma, tendo o índice de Sharpe como critério de eficiência, o portfólio do Minimax pode ser considerado o mais eficiente dentre os analisados, seguido do MP, MV e Ibovespa.

Em vários aspectos considerados até aqui, o Minimax apresentou resultado significativamente melhor que os demais, com maior retorno acumulado no período e maior valor no índice de Sharpe. Além disso, foi o único a possuir maior retorno que o índice de mercado durante quase todo o período analisado. Assim, pode-se considerá-lo como o mais eficiente que aqueles derivados dos outros modelos e do portfólio teórico de mercado (Ibovespa).

Um aspecto importante, que deve ser analisado, é a viabilidade desses modelos para uso cotidiano pelos investidores em ações. A Tabela 1 ressalta alguns aspectos que influenciam as decisões sobre o modelo que seria mais adequado à seleção do portfólio, nas condições apresentadas (alta de mercado e um universo de escolha de 50 ações).

\footnotetext{
${ }^{17} \mathrm{O}$ Índice de Sharpe pode ser descrito pela fórmula apresentada na $4^{\circ}$ linha da Tabela 1 . As variáveis que o
} compõem também são apresentadas na mesma tabela. 
Tabela 1 - Concentração e dispersão dos portfólios selecionados utilizando-se 50 ações (set. 1999 - ago. 2000)

\begin{tabular}{l|c|c|c}
\hline \multicolumn{1}{c|}{ Modelos } & MV & MINIMAX & MP \\
\hline T: Taxa de retorno média/mês (\%) & 3.91 & 5.09 & 4.84 \\
\hline $\begin{array}{l}\text { Z: Desvio-padrão da taxa de } \\
\text { retorno/mês (\%) }\end{array}$ & 7.18 & 10.38 & 9.83 \\
\hline (T-L)/Z: Índice de Sharpe & 0.347 & 0.354 & 0.348 \\
\hline Número médio de ações no portfólio & 22.42 & 5.92 & 5.92 \\
\hline Ação com máxima parcela & 39.56 & 67.09 & 63.95 \\
\hline $\begin{array}{l}\text { Ação com mínima parcela } \\
\text { Soma das 5 ações com maior percentual } \\
\text { na formação do portfólio }\end{array}$ & 172.47 & 271.16 & 252.08 \\
\hline $\begin{array}{l}\text { Soma das 10 ações com maior } \\
\text { percentual na formação do portfólio }\end{array}$ & 291.77 & 442.11 & 428.05 \\
\hline $\begin{array}{l}\text { Numero de ações com percentual na } \\
\text { formação do portfólio menor que 3 \% }\end{array}$ & 137 & 8.99 & 9.82 \\
\hline $\begin{array}{l}\text { Numero de ações com percentual na } \\
\text { formação do portfólio menor que 1 \% }\end{array}$ & 75 & 1 & 2 \\
\hline \hline Fonte: Farias (2003). & & & 9 \\
\hline
\end{tabular}

Fonte: Farias (2003).

Como se pode observar na Tabela 1, o portfólio selecionado, que apresentou maior diversificação, foi o de MV, com um número médio de ações de 22,42, quase quatro vezes maior que o Minimax e o MP. Isso indica um provável custo superior do MV em relação aos demais, além do inconveniente de se ter que alocar o orçamento em grande número de pequenas parcelas. 
Outro fator que demonstra a maior pulverização do portfólio de MV é o número de ações, cujo percentual na alocação ótima foi menor que $3 \%$ e $1 \%$. O portfólio do modelo MV foi drasticamente mais pulverizado que os demais, visto que apresentou 137 ações com percentual na formação menor que $3 \%$, e 75 ações menores que $1 \%$. Esse aspecto constitui uma desvantagem em relação aos demais, uma vez que o elevado número de ações com baixo percentual na formação do portfólio proporcionará, significativamente, maiores custos de transação que os demais. Além disso, se os custos forem muito altos, poderão consumir os ganhos advindos da utilização do modelo, em comparação com uma carteira do mercado ou taxas pré-fixadas, como o CDI.

O portfólio do MV foi o menos concentrado, o que pode ser observado pela soma das 5 e das 10 ações com maiores parcelas na sua formação, apresentada na Tabela 1. O segundo a apresentar menor concentração foi o MP, seguido do Minimax. Os modelos utilizados, à exceção do MV, apresentaram portfólios com níveis de concentração bastante semelhantes.

\subsection{Resultados do $2^{\circ}$ período: janeiro de 2001 a dezembro de 2001}

Nesse período, o CDI apresentou maior retorno que os portfólios dos modelos (Figura 2). Os porfólios do Minimax e do MP proveram soluções somente no primeiro mês e conservaram o retorno deste durante todo o período. O Minimax acumulou perda, ao final do período, de $4,25 \%$ e o MP, de $-4,44 \%^{18}$. Assim, foram os modelos que proporcionaram melhores retornos. O MV, em todo o período, apresentou retornos acumulados menores que os demais portfólios dos modelos, obtendo, ao final do período, uma perda substancial de $-29,74 \%$.

A Figura 2 apresenta os retornos acumulados dos portfólios dos modelos e do Ibovespa. Os formados a partir dos modelos Minimax, MP, pro-

\footnotetext{
${ }^{18} \mathrm{O}$ Índice de Sharpe não é aplicável quando os portfólios apresentam retornos médios negativos, por isso, neste item 3.2 e no 3.3, não foram expostos os valores do referido índice. A concentração e a dispersão dos portfólios Minimax e MP não foram avaliadas, uma vez que estes não apresentaram soluções em grande parte dos meses avaliados.
} 
porcionaram retornos maiores que o Ibovespa, ao final do período. Já o portfólio do MV proporcionou retornos inferiores a este, em todo o período analisado.

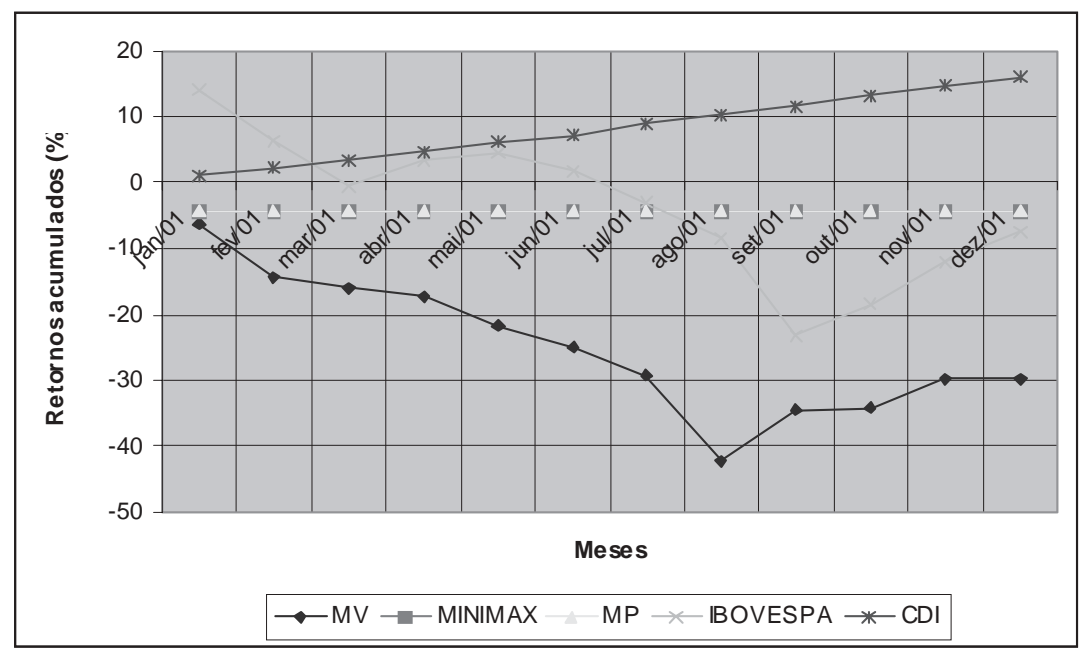

Fonte: Farias (2003).

Figura 2 - Retornos acumulados pelos portfólios selecionados, Ibovespa e CDI, utilizando-se 50 ações (jan. 2001 - dez. 2001).

Os modelos Minimax e MP não geraram soluções, como ressaltado anteriormente, à exceção do mês de janeiro de 2001, nesse cenário de baixa do mercado acionário. Com isso, conseguiram alcançar os melhores resultados dentre os modelos, restringindo suas perdas. Cabe ressaltar que já, só que estes dois modelos não encontraram soluções viáveis para alocação do orçamento, este poderia ser alocado em outros ativos livres de risco, como o CDI. Dessa forma, essa estratégia proporcionaria, seguramente, retornos acumulados positivos ao longo do período analisado. 


\subsection{Resultados do $3^{\circ}$ período: fevereiro de 2002 a janeiro de 2003}

Nesse período, os portfólios gerados a partir dos diversos modelos produziram resultados bastante diversificados. Dois geraram retornos acumulados positivos ao final do período, porém, um apresentou grande perda. Na Figura 3, verifica-se que somente os portfólios do Minimax e do MP obtiveram retornos acumulados positivos, com 18,19 e 9,81 pontos percentuais, respectivamente. Destes, somente o Minimax gerou retornos superiores ao CDI, em apenas 0,14 pontos percentuais.

Na Figura 3, observa-se que os modelos baseados nos princípios do Minimax e MP apresentaram comportamento distinto do MV, visto que, até o mês de agosto de 2002, não apresentaram soluções, ou as alocações nos ativos deveriam ser 0 . A partir desse mês, os modelos apresentaram soluções que resultaram em retornos acumulados positivos.

Como já ressaltado, os modelos Minimax e MP apresentaram vantagem significativa sobre o modelo $\mathrm{MV}$, que é a característica de não gerar soluções em que as variáveis têm valores zero, quando os cenários são desfavoráveis. Assim, no período de fevereiro a agosto de 2002, o investidor que baseasse suas estratégias de investimento nesses modelos poderia investir seus recursos em outras alternativas, em vez de investi-los no mercado acionário. Se ele investisse seus recursos no CDI, de fevereiro a agosto de 2002, e no mercado acionário, no restante do período, teria um retorno acumulado de $28 \%$, pelo Minimax, e de $19,6 \%$, pelo MP.

Quando se compara o desempenho das estratégias baseadas nos modelos com a carteira teórica do Ibovespa, percebe-se que todos os modelos obtiveram retornos acumulados significativamente maiores que o índice, como pode ser observado na Figura 3. 


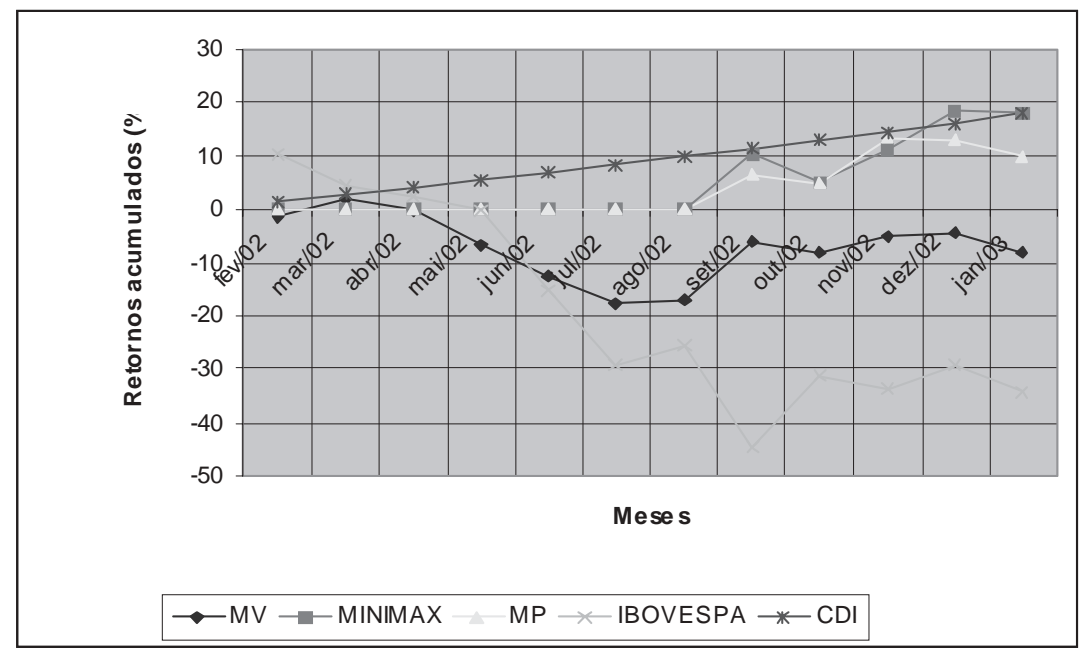

Fonte: Farias (2003).

Figura 3 - Retornos acumulados pelos portfólios selecionados, Ibovespa e CDI, utilizando-se 50 ações (fev. 2002 - jan. 2003).

\subsection{Análise conjunta dos resultados}

Na Figura 4, foram apresentados os retornos acumulados dos portfólios ao final dos três períodos considerados. Todos os modelos, no primeiro período, proporcionaram retornos acumulados superiores ao CDI e no segundo e no terceiro, inferiores, à exceção do portfólio gerado pelo Minimax no último período.

Todos os portfólios gerados pelos modelos apresentaram retornos acumulados positivos no $1 .^{\circ}$ período (alta de mercado), os quais reduziram, drasticamente, no 2. ${ }^{\circ}$ (baixa de mercado) e tiveram pequeno crescimento no $3 .^{\circ}$ (baixa de mercado), como se pode observar na Figura 4. No período inicial, todos os portfólios obtiveram retornos acumulados maiores que o Ibovespa; no segundo, somente o Minimax e o MP tiveram acúmulo de retornos superior ao Ibovespa; e no terceiro e no último período, os três portfólios apresentaram maiores retornos acumulados 
que o Ibovespa. Dessa forma, somente os modelos Minimax e MP apresentaram retornos acumulados, sistematicamente, superiores ao índice de mercado (Ibovespa), destacando-se o portfólio do Minimax, que apresentou maiores retornos acumulados que os demais durante os três períodos estudados. $\mathrm{O} \mathrm{MV}$, somente no $2^{\circ}$ período, obteve retorno acumulado menor que o Ibovespa.

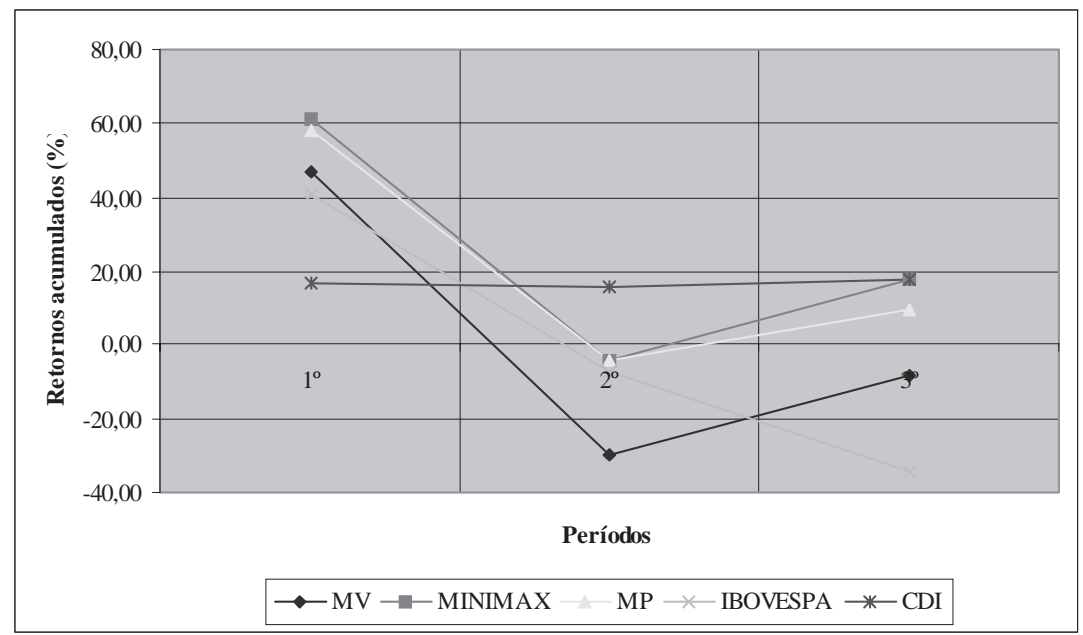

Fonte: Farias (2003).

Figura 4 - Retornos acumulados pelos portfólios selecionados, CDI e IBOVESPA, nos períodos de set. 1999 a ago. 2000, jan. 2001 a dez. 2001 e fev. 2002 a jan. 2003.

\section{Conclusões}

Neste estudo, buscou-se comparar e analisar os modelos de seleção de portfólio Média-Variância (modelo teórico), Minimax e Minimax Ponderado (modelos analíticos), no mercado acionário brasileiro. O trabalho foi realizado a partir das 50 ações mais negociadas na Bovespa, nos períodos de setembro de 1999 a agosto de 2000; janeiro a dezembro de 
2001; e fevereiro de 2002 a janeiro de 2003. Os modelos geraram portfólios ótimos para cada mês, com base em retornos dos últimos 12 meses. Foi realizada uma análise ex-post, na qual se obtiveram os retornos dos portfólios selecionados por cada modelo. Foram avaliados diversos aspectos dos portfólios gerados pelos modelos, como retornos acumulados, eficiência, diversificação e pulverização. Essa avaliação é importante para orientar o investidor na escolha do modelo de seleção de portfólio em diferentes contextos econômicos.

De maneira geral, os portfólios gerados pelos modelos analisados no período em que o mercado esteve em alta (setembro de 1999 a agosto de 2000) apresentaram retornos acumulados significativamente superiores ao acumulado da taxa do CDI. Todavia, quando o mercado esteve em baixa, os portfólios formados pelos modelos proporcionaram retornos acumulados inferiores, à exceção do gerado pelo Minimax no $3^{\circ}$ período. Dessa forma, a utilização dos modelos foi mais apropriada em períodos em que o mercado esteve em alta, visto que proporcionaram retornos acumulados superiores a CDI, em todos os 12 meses do período.

O modelo MV proporcionou portfólios que, em certas circunstâncias, obtiveram retorno superiores e, em outras, inferiores ao da Ibovespa. $\mathrm{O}$ Minimax destacou-se por apresentar maiores retornos acumulados ao final do período, do que os portfólios gerados pelo MP, MV e Ibovespa. Os modelos Minimax e MP geraram portfólios que apresentaram retornos acumulados maiores que o referido índice, nos três períodos analisados.

Essa característica apresentada pelos modelos Minimax e MP torna-os muito atrativos e distingue-os dos demais, uma vez que, em todos dos casos analisados, eles apresentaram resultados superiores ao portfólio do Ibovespa. Dessa forma, esses modelos podem ser considerados os mais adequados, dentre os analisados, à obtenção de retornos acumulados maiores que o mercado (representado pelo referido índice) com o número de 50 ações no universo de escolha. 
O portfólio gerado pelo MV apresentou a menor eficiência, em comparação com os demais, no período de setembro de 1999 a agosto de 2000, pois obteve um valor do índice de Sharpe próximo, porém menor, que os do Minimax e o MP.

Na utilização prática do MV há dificuldades de obtenção de soluções, em razão de sua pulverização e computacionais, associados à resolução de sua forma quadrática a larga escala. Assim, visto que essas dificuldades podem inviabilizar a utilização do MV como modelo de seleção de portfólios em larga escala, o Minimax torna-se o mais apropriado neste contexto, seguido do MP, devido à sua fácil operacionalização e à obtenção de maior eficiência e retornos acumulados.

Além disso, não se podem comprar quantidades fracionárias de ações, ou abaixo da unidade mínima de negociação. Uma solução encontrada é a Programação Inteira, visto que para os modelos que têm a forma linear, MP e o Minimax, esse tipo de programação pode ser realizado sem muitas dificuldades, superando facilmente esse problema. Já no modelo $\mathrm{MV}$, a programação inteira seria difícil, devido à sua forma nitidamente não-linear.

\section{Referências Bibliográficas}

BOVESPA. Informe técnico: composição dos índices. [01 jun. 2003]. (http://www.bovespa.com.br).

FARIAS, C. A. Modelos de otimização de portfolios: análise comparativa e aplicações ao mercado acionário brasileiro. Dissertação (Economia Aplicada) - Universidade Federal de Viçosa. Viçosa: UFV, 2003. 98 .

FIGUEIREDO, A.C. et al. A utilização da teoria de carteiras de Markowitz e do modelo de índice único de Sharpe no mercado de ações brasileiro em 1999. Resenha BM\&F, n. 141, p. 51-59, set./out. 2000. 
GASTINEAU, G.L., KRITZMAN, M.P. Dicionário de administração de risco financeiro. São Paulo: BMF Brasil, 1999.

IPEADATA. Dados macroeconômicos e regionais. [15 set. 2002]. (http://www.ipeadata.gov.br/).

KONNO, H., YAMAZAKI, H. Mean-absolute deviation portfolio optimization model and its applications to Tokyo stock market. Management Science, v. 37, n. 5, p. 519-531, 1991.

KROLL, Y., LEVI, H., MARKOWITZ, H. Mean-variance versus direct utility maximization. Journal of Finance, v. 39, p. 47-62, 1984.

MARKOWITZ, H. Portfolio selection. The Journal of Finance, v. 7, n. 1, p. 77-91, mar. 1952.

PANG, J.S. A new efficient algorithm for a class of portfolio selection problems. Operational Research, v. 28, p. 754-767, 1980.

PAPAHRISTODOULOU, C. Optimal portfolios using linear programming models. Västeras, Sweden: Mäkardaken University, 2003. (Working paper).

PEROLD, A. Large scale portfolio optimizations. Management Science, v. 30, p. 1143-1160, 1984.

SANDRONI, P. Portfolio. In: Dicionário de Economia. São Paulo: Best Seller, 2000. 615 p.

SHARPE, W.F. A linear programming approximation for the general portfolio selection problem. Journal of Financial Quantitative Anal., v. 6, p. 1263-1275, 1971.

SHARPE, W.F. A linear programming algorithm for a mutual fund portfolio selection. Management Science, v. 13, p. 499-510, 1967. 
SHARPE, W.F. Capital asset prices: a theory of market equilibrium under conditions of risk. Journal of Finance, n. 19, p. 425-442, 1964.

SHARPE, W.F. A simplified model for portfolio analysis. Management Science, v. 9, p. 277-293, 1963.

SIMAAN, Y. Estimation risk in portfolio selection: the mean absolute deviation model. Management Science, v. 43, p. 1437-1446, 1997.

STONE, B.K. A linear programming formulation of the general portfolio selection problem. Journal of Financial Quantitative Anal., v. 8, p. 621-636, 1973.

WEBER, J.E. Matemática para economia e administração. 2.ed. São Paulo: Harbra, 1986. 674 p.

YOUNG, M.R.A. Minimax portfolio selection rule with linear programming solution. Management Science, v. 44, p. 673-683, 1998.

\begin{abstract}
The objective of this paper was to compare and to analyze three portfolio selection models: Mean-Variance, Minimax and Minimax Weighted. These models were evaluated using historical data (September 1999 to August 2000, January 2001 to December 2001 and February 2002 to January 2003) obtained from the Brazilian Stock Market (Bovespa). They were selected optimal portfolios to each month based on the returns of the last twelve months. The results show that the returns obtained through the Mean-Variance model were superiors in certain circumstances and inferiors in others when compared to the Ibovespa index. The Minimax model obtained the best accumulated returns when compared with the others models and the Ibovespa index.
\end{abstract}

Key-words: portfolio selection, Mean-variance, Bovespa, game theory 